\title{
Mapping the antigenic determinants and reducing the immunogenicity of trichosanthin by site-directed mutagenesis
}

\author{
Qunxing $\mathrm{An}^{1,2}$, Sanhua $\mathrm{Wei}^{1}$, Shijie $\mathrm{Mu}^{2}$, Xianqing Zhang ${ }^{2}$, Yingfeng Lei ${ }^{1}$, Wei Zhang ${ }^{1}$, \\ Ning Jia ${ }^{1}$, Xiaodong Cheng ${ }^{3}$, Ailing Fan ${ }^{3}$, Zhidong Li $^{1}$ \& Zhikai Xu ${ }^{1}$ * \\ ${ }^{1}$ Department of Microbiology, Fourth Medical University of PLA, Xi'an, 710032, China; ${ }^{2}$ Department of \\ Blood Transfusion, Xijing Hospital, Fourth Medical University of PLA, Xi'an, 710033, China, ${ }^{3}$ Department \\ of Clinical Laboratories, Xijing Hospital, Fourth Medical University of PLA, Xi'an, 710033, China
}

Received 25 January 2006; accepted 1 June 2006

(C) 2006 National Science Council, Taipei

Key words: human immunodeficiency virus, immunogenicity, ribosome-inactivating protein, site-directed mutagenesis, trichosanthin

\begin{abstract}
Summary
Trichosanthin (TCS) is a type I ribosome-inactivating protein (RIP) possessing multiple pharmacological properties. One of its interesting properties is to inhibit human immunodeficiency virus (HIV) replication but its strong immunogenicity has limited the repeated clinical administration. To map the antigenic determinants and reduce the immunogenicity of TCS, two potential antigenic sites (YFF81-83 and KR173-174) were identified by computer modeling, and then three TCS mutants namely TCS $_{\text {YFF81-83ACS, }}$ TCS KR173-174CG, and TCS $_{\text {YFF-KR }}$ were constructed by site-directed mutagenesis. The RI activity and DNase-like activity of the three constructed TCS mutants were similar to natural TCS but with much lower immunogenicity. Results suggested that the two selected sites are all located at or near the antigenic determinants of TCS. In toxicity studies, the $\mathrm{LD}_{50}$ of the three TCS mutants was not different from natural TCS. These findings would be useful in designing a better therapeutic agent for AIDS.
\end{abstract}

\section{Introduction}

Trichosanthin (TCS) is a $27 \mathrm{kDa}$ active plant protein isolated from the root tuber of the Chinese medicinal herb Trichosanthes kirilowii Maximowicz. It is processed from a larger precursor protein, containing a 23 amino acid amino $(\mathrm{N})$ terminal sequence (pre sequence) and a 19 amino acid carboxy (C)-terminal extension (pro sequence). TCS is classified as a type I ribosomeinactivating protein (RIP) that cleaves specifically the N-glycosidic bond of A-4324 of 28S rRNA and

*To whom correspondence should be addressed. Fax + 86-298477-4523, E-mail: zhikaixu@fmmu.edu.cn

Qunxing An and Sanhua Wei equally contribute to this work. inhibits protein synthesis [1-3]. TCS also has DNase-like activity and cleaves the supercoiled double-stranded DNA to produce nicked circular and linear DNA [4]. Recently, TCS has been found to stimulate the production of reactive oxygen species (ROS) and induce apoptosis [5-8], enhance the action of chemokines and inhibit human immunodeficiency virus type 1 (HIV-1) integrase [9-11].

TCS has multiple pharmacological properties including anti-tumor, immunomodulatory and antiviral activity [12-15]. It is traditionally used to induce mid-term abortion in china. In the late 1980s, TCS was the first RIP found to possess anti-HIV activity. It preferentially inhibited the replication of HIV-1 in both acutely infected 
T-lymphoblastoid cells and chronically infected macrophages in vitro [16]. Therefore, it is also a potential therapeutic agent for AIDS. Clinical trials demonstrated that HIV infected patients failing treatment with antiretroviral agent such as zidovudine showed a significant decrease of the serum HIV-1 p24 antigen level and an increase of the percentage of $\mathrm{CD} 4{ }^{+} \mathrm{T}$-lymphocytes when TCS is added to the antiretroviral agent regimen [1719]. However, strong immunogenicity of this compound hindered its further development into an anti-HIV therapeutic agent. As a protein foreign to a host, TCS elicits specific antibodies such as $\operatorname{IgG}$ and $\operatorname{IgE}[19,20]$. Repeated uses will result in severe anaphylactic reaction leading to death.

Since the TCS crystal structure [21, 22] is available, we can use three-dimensional computer modeling to analyze the potential antigenic sites. The following major parameters were considered: hydrophilicity, exposure on the surface, chain flexibility, and formation of loops or turns. Two sites, YFF81-83 and KR173-174 with higher antigenic index and remote from the active cleft were selected. The objective of this study was to construct the TCS mutants and examine its immunogenicity and biological activities.

\section{Materials and methods}

\section{Reagents and bacterial strains}

Natural TCS (nTCS) was purified from the root tuber of Trichosanthes kirilowii and obtained from Jinshan Pharmaceutical Limited Company (Shanghai, China). Anti-TCS rabbit antiserum was prepared in our laboratory using purified nTCS as immunogen. The restriction endonucleases, T4 DNA ligase and Taq DNA polemerase were purchased from Promega. The Ni-NTA purification system, expression vector pRSET-A, $E$. coli $\mathrm{DH} 5 \alpha$ and $E$. coli BL21 (DE3) came from Invitrogen. All other chemicals were of analytical grade.

\section{Site-directed mutagenesis}

By computer modeling based mainly on hydrophilicity, exposure on the surface, chain flexibility, and formation of loops or turns, two sites namely, YFF81-83 and KR173-174 were identified as potential antigenic sites of TCS. By site-directed mutagenesis, the two sites, YFF81-83 and KR173-174, were replaced by ACS81-83 and CG173-174 respectively, three TCS mutants namely TCS YFF81-83ACS, $_{\text {TCS }}$ KR173-174CG $_{\text {and }}$ TCS $_{\text {YFF81-83ACS-KR173-174CG }}$ (TCS YFF-KR $_{\text {. }}$ ) were constructed by polymerase chain reaction using the overlapping primer method [23]. The PCRamplified DNA fragments were confirmed by dideoxy DNA sequencing to ensure that no secondary mutation had occurred.

\section{Protein expression and purification}

By site-directed mutagenesis, the wild-type TCS (wTCS) and mutant TCS (mTCS) genes were digested with BamHI and EcoRI, cloned into pRSET-A (This vector contains a $6 \times$ histidine affinity tag for ease of purification, Invitrogen), and then transformed to E. coli BL21 (DE3). The transformed E. coli strains were cultured at $37^{\circ} \mathrm{C}$ in LB medium with ampicillin $(100 \mu \mathrm{g} / \mathrm{ml})$ until the cell density reached $\mathrm{OD}_{600}=0.6$. Then, the IPTG was added to a final concentration of $0.1 \mathrm{mM}$ and the cells were cultured at $37^{\circ} \mathrm{C}$ for $4 \sim 5 \mathrm{~h}$. Collect the bacteria and Resuspend all pellets in lysis buffer using the Ni-NTA purification system for native purification according to the instructions (Invitrogen).

\section{Characterization of the expressed proteins}

The purity and molecular weight of the expressed proteins were determined by $12 \%$ SDS-PAGE. Immunological analysis was performed by western blot analysis using anti-TCS rabbit antiserum as the first antibody.

\section{DNase activity assay}

The assay for DNase-like activity of TCS was carried out according to a previously described method [4]. In brief, $1 \mu \mathrm{g}$ supercoiled DNA (pUC19) was incubated with $2 \mu \mathrm{g}$ of various forms of TCS in a total volume of $20 \mu \mathrm{l}$ of $50 \mathrm{mM}$ Tris$\mathrm{HCl}, 10 \mathrm{mM} \mathrm{MgCl}_{2}, 10 \mathrm{mM} \mathrm{CaCl}, 100 \mathrm{mM}$ $\mathrm{NaCl}, \mathrm{pH} 8.0$ at room temperature for $1 \mathrm{~h}$. After finished the incubation, the electrophoresis was carried out under non-denaturing conditions in 
standard TAE buffer in 1.2\% agarose gel at $50 \mathrm{~V}$ until the tracking dyes moved to the appropriate positions. The gel was stained with ethidium bromide $(0.5 \mu \mathrm{g} / \mathrm{ml})$, and then photographed on a UV transilluminator.

\section{Ribosome inactivating activity assay}

The inhibitory activity of nTCS and its derivatives on protein synthesis in vitro was determined by measuring the incorporation of $\left[{ }^{3} \mathrm{H}\right]$-leucine into protein in a rabbit reticulocyte lysate cell-free system (Promega). The assay was based on that of Pelham et al. [24] using an untreated rabbit reticulocyte lysate as a source of ribosome, mRNA, and other endogenous factors. Briefly, various amounts of nTCS or its derivatives were mixed with $11.5 \mu \mathrm{l}$ of rabbit reticulocyte lysate in $20 \mathrm{mM}$ Tris- $\mathrm{HCl}$ (pH 7.8) containing $4 \mathrm{mCi} / 1\left[{ }^{3} \mathrm{H}\right]$-leucine, $1.5 \mathrm{mM} \mathrm{MgCl}{ }_{2}, 5 \mathrm{mM}$ dithiothreitol, and $50 \mathrm{mM} \mathrm{KCl}$, followed by incubation at $30{ }^{\circ} \mathrm{C}$ for $90 \mathrm{~min}$. The reactions were precipitated with $25 \%$ trichloroacetic acid and collected on glass microfiber filters by filtration with Whatman GF/C, and the radioactivities were determined with a liquid scintillation counter. Each reported inhibition point is calculated as the mean of triplicate individual tests.

\section{Assay for immunogenicity: $\operatorname{Ig} G$ and $\operatorname{Ig} E$ responses}

BALB/c mice (6 7-weeks-old, about $20 \mathrm{~g}$ ) were used for the experiment. Mice in groups of five were immunized subcutaneously at the back with $8 \mu \mathrm{g}$ of various forms of TCS. Booster injections were given 2 weeks after the first immunization. Then blood samples were collected from each mouse 1 week after the immunization, and sera were stored at $-20{ }^{\circ} \mathrm{C}$ for later assay. Specific IgG and IgE antibodies against TCS were detected by ELISA. ELISA plates were coated with antigen $(10 \mu \mathrm{g} / \mathrm{ml} \mathrm{nTCS})$ overnight at $4{ }^{\circ} \mathrm{C}$ with coating buffer. After washing several times with PBST, serum samples were added to the ELISA plates at $100 \mu \mathrm{l}$ per well. Then biotin-conjugated rat antimouse IgE, streptavidin-HRP, or HRP-conjugated goat anti-mouse IgG antibodies were added after incubation and washing. Finally, $50 \mu \mathrm{l}$ substrate OPD were added and incubated at $37^{\circ}$ for $20 \mathrm{~min}$. Optical density was measured by ELISA reader at $490 \mathrm{~nm}$.
Acute toxicity assay

Female and male BALB/c mice (6 7-weeks-old, about $20 \mathrm{~g}$ ) were divided into five groups of 7 each. Each group of animals was injected i.v. with various forms of TCS in a dose of $31.50,22.05$, $15.44,10.80$ and $7.56 \mathrm{mg} / \mathrm{kg}$ body weight. Mortality of these animals was monitored up to 10 days after administration. The $\mathrm{LD}_{50}$ is the calculated dose of various forms of TCS that kills $50 \%$ of the animals.

\section{Results}

Mutation, expression, and purification of TCS

In this study, computer prediction of antigenic determinants was adopted to analyze the potential antigenic sites based on hydrophilicity, exposure on the surface, chain flexibility, and formation of loops or turns. Two sites, YFF81-83 and KR173174, were selected (Fig. 1). YFF81-83 are all aromatic amino acid with larger side chain and are located at the surface of the TCS molecule. KR173-174 have long and positively charged sidechains, which can form a hydrophilic surface with higher polarity than other residues. In addition, the computer prediction showed that the antigenic indexes of YFF81-83 and KR173-174 are much higher and may involve in the formation of TCS antigenic determinants.

By site-directed mutagenesis, the two selected sites were mutated as follows: Tyr81-Phe82-Phe83 to Ala81-Cys82-Ser83, and Lys173-Arg174 to

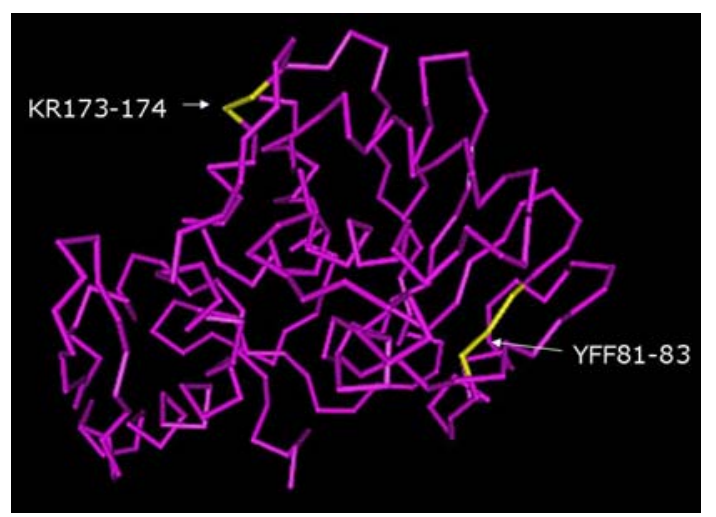

Figure 1. The three-dimensional structure of trichosanthin indicating the location of YFF81-83 and KR173-174. 
Cys173-Gly174, respectively. Three TCS mutants namely TCS YFF81-83ACS, $_{\text {TCS }}$ KR173-174CG and TCS $_{\text {YFF81-83ACS-KR 173-174CG }}$ (TCS YFF-KR $_{\text {Y }}$ ) were constructed by PCR using appropriate mutagenic primers. As for the choice of residues that were used to substitute these identified antigenic sites, we usually select the amino acid with smaller molecule and shorter side chain that is not possibly involved in the construction of antigenic determinants, such as Gly, Ala and Ser etc. according to our experiences. TCS is a polypeptide without cysteine residues. In this study, a cysteine residue has been introduced by site-directed mutagenesis to TCS at Phe82 and Lys 173 respectively, and then site-directed PEGylation of TCS can be possible.

To express the various forms of TCS, the plasmid pRSET containing the wild-type TCS (wTCS) or mutant TCS (mTCS) gene was expressed at high level in E. coli strain BL21 (DE3). All the TCS protein were expressed in soluble form and purified with the Ni-NTA native purification system. After expression and purification, SDS-PAGE and Western blotting were used to detect the recombinant wTCS and mTCS protein (Fig. 2).

\section{DNase activity}

Under normal enzymatic digestion conditions, TCS cleaves the supercoiled double-stranded DNA to produce nicked circular and linear DNA. To demonstrate the DNase activity of the expressed TCS proteins, supercoiled DNA (pUC19) was incubated with various forms of TCS. As shown in Fig. 3, all of them exhibited the DNase-like activity, suggesting that the expressed wTCS and mTCS had a similar functional activity to nTCS.

\section{Ribosome inactivating activity}

Rabbit reticulocyte lysate cell-free system was used to estimate the ribosome inactivating (RI) activity of various forms of TCS. As shown in Table 1, the ability of expressed wTCS and mTCS to inhibit protein synthesis in vitro is comparable with that of nTCS, the $\mathrm{IC}_{50}$ values of nTCS,

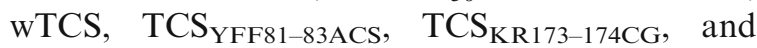
TCS $_{\text {YFF-KR }}$ were $4.69 \pm 0.30, \quad 5.06 \pm 0.29$, $4.95 \pm 0.22,5.34 \pm 0.32$, and $5.30 \pm 0.25 \mathrm{ng} /$ $\mathrm{ml}$, respectively.

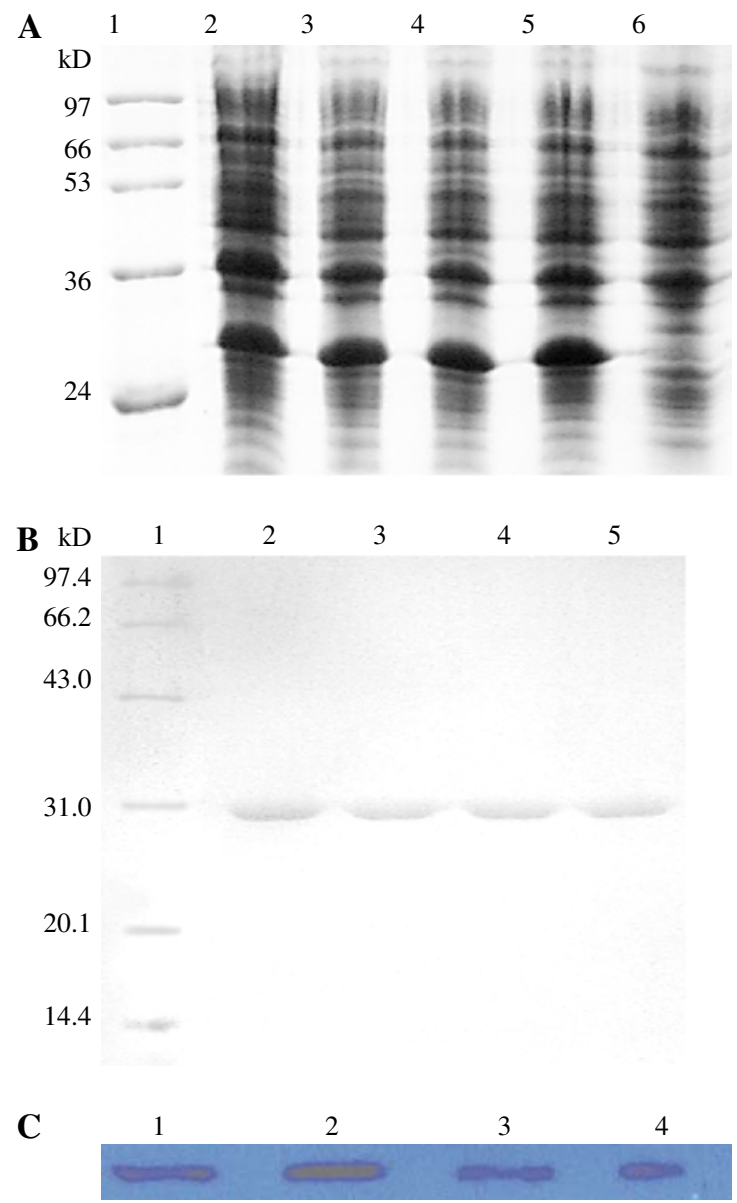

Figure 2. (A) Analysis of expressed TCS and its mutants by $12 \%$ SDS-PAGE. The gel was stained using Coomassie brilliant blue. Lane 1, molecular weight marker; lane 2, 3, 4 \& 5, proteins extracted from E. coli strain BL21 (DE3) transformed with recombinant plasmid pRSET-wTCS,

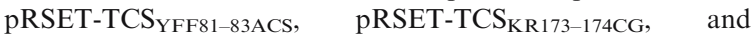
pRSET-TCS from $E$. coli strain BL21 (DE3) transformed with empty plasmid pRSET were served as negative control. (B) Purification of expressed TCS and its mutant proteins using $\mathrm{Ni}$ NTA native purification system. Lane 1 , molecular weight

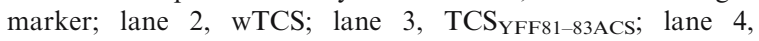
TCS $_{\text {KR173-174CG; }}$; lane 5, TCS and its mutant proteins were confirmed by western blot analysis using anti-TCS rabbit antiserum as the first anti-

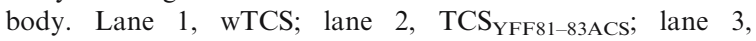
TCS $_{\text {KR173-174CG; lane } 4 \text {, TCS }}$ YFF-KR.

\section{Immunogenicity: $\operatorname{Ig} G$ and $\operatorname{Ig} E$ responses}

Mice were immunized with various forms of TCS, and the sera IgG and IgE levels determined by ELISA are shown in Fig. 4. It appeared that all the mTCS produced a lower 


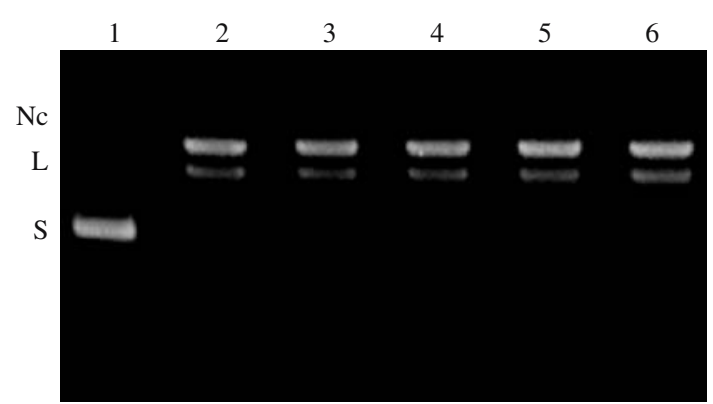

Figure 3. The DNase-like activity of TCS and its mutants on supercoiled pUC19 DNA. Supercoiled pUC19 DNA was incubated with various forms of TCS under normal enzymatic digestion conditions for $1 \mathrm{~h}$. Then, the electrophoresis was carried out in $1.2 \%$ agarose gel and the gel was stained with ethidium bromide. Lane 1, Supercoiled pUC19 DNA was served as negative control; lane 2, 3, 4, 5 \& 6, Supercoiled pUC19 DNA was incubated with nTCS, wTCS, TCS $_{\text {YFF81-83ACS, }}$ TCS KR173-174CG, and $_{\text {TCS }}$ YFF-KR respectively. Nc, nicked circular DNA; L, linear DNA; S, supercoiled DNA.

Table 1. The summary of RI activity and acute toxicity of TCS and its mutants.

\begin{tabular}{lll}
\hline Protein species & $\begin{array}{l}\text { RI activity } \\
\left(\mathrm{IC}_{50}, \mathrm{ng} / \mathrm{ml}\right)\end{array}$ & $\begin{array}{l}\text { Acute toxicity } \\
\left(\mathrm{LD}_{50}, \mathrm{mg} / \mathrm{kg}\right)\end{array}$ \\
\hline $\mathrm{nTCS}$ & $4.69 \pm 0.30$ & 13.64 \\
$\mathrm{wTCS}$ & $5.06 \pm 0.29$ & 13.71 \\
$\mathrm{TCS}_{\text {YFF81-83ACS }}$ & $4.95 \pm 0.22$ & 14.35 \\
TCS $_{\text {KR173-174CG }}$ & $5.34 \pm 0.32$ & 13.02 \\
TCS $_{\text {YFF-KR }}$ & $5.30 \pm 0.25$ & 13.71 \\
\hline
\end{tabular}

The RI activity of TCS and its mutants was assessed by inhibition $\left[{ }^{3} \mathrm{H}\right]$-leucine incorporation, and acute toxicity is represented by dose to kill $50 \%$ of the mice $\left(\mathrm{LD}_{50}\right)$.

IgE response than wTCS and nTCS, while the IgG response of mTCS was not much different from wTCS and nTCS.

\section{Acute toxicity}

For toxicity studies, several different doses of each type of TCS were injected intravenously into $\mathrm{BALB} / \mathrm{c}$ mice and mortality was monitored up to 10 days after administration. The $\mathrm{LD}_{50}$ of TCS and its mutants is summarized in Table 1. Acute toxicity of expressed wTCS and mTCS was not different from nTCS, and their $\mathrm{LD}_{50}$ values were about $14.0 \mathrm{mg} / \mathrm{kg}$.

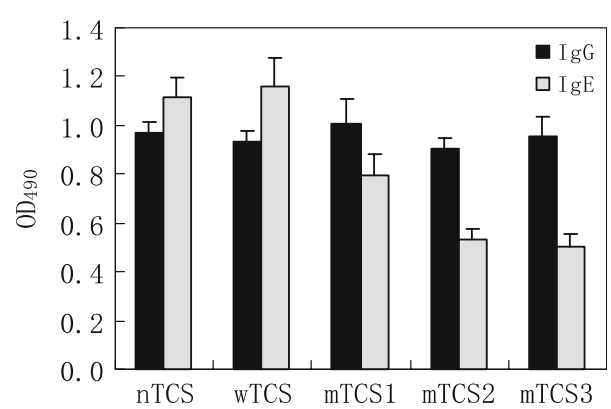

Figure 4. Mice in groups of five were immunized with various forms of TCS, and blood samples were collected from each mouse after immunization. Specific IgG and $\operatorname{IgE}$ antibodies

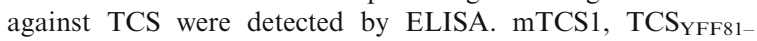
83ACS; mTCS2, TCS KR 173-174CG $_{17 T C S 3,}$ TCS YFF-KR. Values are means $\pm \mathrm{SD}(n=6)$.

\section{Discussion}

Although TCS has multiple biological and pharmacological activities, its strong immunogenicity hindered the further development into a therapeutic agent. In this study, to map the antigenic determinants and reduce the immunogenicity of TCS, computer modeling was adopted to select the potential antigenic sites. Two sites were selected: YFF81-83 and KR173-174. By site-directed mutagenesis, three TCS mutants namely TCS $_{\text {YFF81-83ACS, }}$ TCS KR173-174CG $_{\text {and TCS }}$ YFFKR were constructed successfully, and expressed at high level in soluble form in E. coli BL21 (DE3) and purified easily to homogeneity by using Ni-NTA purification system.

TCS is classified as a type I RIP that inhibits protein synthesis [1-3]. It is generally believed that the anti-HIV activity of TCS is related to its RI activity. TCS also has DNase-like activity and cleaves the supercoiled double-stranded DNA to produce nicked circular and linear DNA [4]. In this study, the RI activity and DNase-like activity of TCS and its mutants were tested. There had no effect on its RI activity and DNase-like activity when mutation of TCS at YFF81-83 and KR173174. This indicated that the overall structure of the three mTCS was probably maintained.

Immunogenicity and acute toxicity of TCS and its mutants were also examined in this study. The results indicated that there was a marked decrease in immunogenicity. This suggests that the two selected sites are all located at or near the antigenic determinants of TCS. In toxicity studies, the $\mathrm{LD}_{50}$ of the three mTCS was not different from nTCS. 
This indicates that mutation of TCS does not bring about significant changes in acute toxicity.

Covalent modification of proteins with polyethylene glycol (PEG) has been widely used to increase plasma half-life and reduce immunogenicity. This method has been proved to be effective with many other molecules [25-30]. TCS is a polypeptide without cysteine residues. In this study, a cysteine residue has been introduced by site-directed mutagenesis to TCS at Phe 82 and Lys173, respectively, and then site-directed PEGylation of TCS can be possible. In the next step, the three promising mTCS will be coupled to PEG via the newly created cysteine residue, and their activities, immunogenicity and pharmacokinetics will be explored further.

In conclusion, this study described a method of combining computer modeling and site-directed mutagenesis to map the antigenic determinants and reduce the immunogenicity of TCS. The in vitro biological activities of the three constructed mTCS were similar to nTCS but with much lower immunogenicity. Results suggested that the two selected sites, YFF81-83 and KR173-174, are all located at or near the antigenic determinants of TCS. These findings would be useful in designing a better therapeutic agent for AIDS.

\section{Acknowledgments}

This work was supported in part by a grant from the Natural Science Foundation of Shaanxi province (2003K10G9).

\section{References}

1. Zhang J.S. and Liu W.Y., The mechanism of action of trichosanthin on eukaryotic ribosomes-RNA N-glycosidase activity of the cytotoxin. Nucl. Acids Res. 20: 1271$1275,1992$.

2. Endo Y., Gluck A., Chan Y.L., Tsurugi K. and Wool I.G., RNA-protein interaction. An analysis with RNA oligonucleotides of the recognition by alpha-sarcin of a ribosomal domain critical for function. J. Biol. Chem. 265: 2216-2222, 1990.

3. Stirpe F., Ribosome-inactivating proteins. Toxicon 44: 371-383, 2004.

4. Li M.X., Yeung H.W., Pan L.P. and Chan S.I., Trichosanthin, a potent HIV-1 inhibitor, can cleave supercoiled DNA in vitro. Nucl. Acids Res. 19: 6309-6312, 1991.

5. Wang Y.Y., Ouyang D.Y., Huang H., Chan H., Tam S.C. and Zheng Y.T., Enhanced apoptotic action of trichosan- thin in HIV-1 infected cells. Biochem. Biophys. Res. Commun. 331: 1075-1080, 2005.

6. Li F., Mei Y., Wang Y., Chen C., Tu J., Xiao B. and Xu L., Trichosanthin inhibits antigen-specific $\mathrm{T}$ cell expansion through nitric oxide-mediated apoptosis pathway. Cell Immunol. 234: 23-30, 2005.

7. Zhang C., Gong Y., Ma H., An C., Chen D. and Chen Z.L., Reactive oxygen species involved in trichosanthininduced apoptosis of human choriocarcinoma cells. Biochem. J. 355: 653-661, 2001.

8. Zhang C.Y., Gong Y.X., Ma H., An C.C. and Chen D.Y., Trichosanthin induced calcium-dependent generation of reactive oxygen species in human choriocarcinoma cells. Analyst 125: 1539-1542, 2000.

9. Xu W., Hou W., Yao G., Ji Y., Yeh M. and Sun B., Inhibition of Th1- and enhancement of Th2-initiating cytokines and chemokines in trichosanthin- treated macrophages. Biochem. Biophys. Res. Commun. 284: 168-172, 2001.

10. Au T.K., Collins R.A., Lam T.L., Ng T.B., Fong W.P. and Wan D.C., The plant ribosome inactivating proteins luffin and saporin are potent inhibitors of HIV-1 integrase. FEBS Lett. 471: 169-172, 2000.

11. Zhao J., Ben L.H., Wu Y.L., Hu W., Ling K., Xin S.M., Nie H.L., Ma L. and Pei G., Anti-HIV agent trichosanthin enhances the capabilities of chemokines to stimulate chemotaxis and $\mathrm{G}$ protein activation, and this is mediated through interaction of trichosanthin and chemokine receptors. J. Exp. Med. 190: 101-111, 1999.

12. Leung K.N., Yeung H.W. and Leung S.O., The immunomodulatory and antitumor activities of trichosanthin-an abortifacient protein isolated from tian-hua-fen (Trichosanthes kirilowii). Asian Pac. J. Allergy Immunol. 4: 111120, 1986.

13. Tsao S.W., Ng T.B. and Yeung H.W., Toxicities of trichosanthin and alpha-momorcharin, abortifacient proteins from Chinese medicinal plants, on cultured tumor cell lines. Toxicon 28: 1183-1192, 1990.

14. Tsao S.W., Yan K.T. and Yeung H.W., Selective killing of choriocarcinoma cells in vitro by trichosanthin, a plant protein purified from root tubers of the Chinese medicinal herb Trichosanthes kirilowii. Toxicon 24: 831-840, 1986.

15. Shaw P.C., Lee K.M. and Wong K.B., Recent advances in trichosanthin, a ribosome-inactivating protein with multiple pharmacological properties. Toxicon 45: 683-689, 2005.

16. McGrath M.S., Hwang K.M., Caldwell S.E., Gaston I., Luk K.C., Wu P., Ng V.L., Crowe S., Daniels J. and Marsh J., GLQ223: an inhibitor of human immunodeficiency virus replication in acutely and chronically infected cells of lymphocyte and mononuclear phagocyte lineage. Proc. Natl. Acad. Sci. USA 86: 2844-2848, 1989.

17. Mayer R.A., Sergios P.A., Coonan K. and O'Brien L., Trichosanthin treatment of HIV-induced immune dysregulation. Eur. J. Clin. Invest. 22: 113-122, 1992.

18. Byers V.S., Levin A.S., Malvino A., Waites L., Robins R.A. and Baldwin R.W., A phase II study of effect of addition of trichosanthin to zidovudine in patients with HIV disease and failing antiretroviral agents. AIDS Res. Hum. Retroviruses 10: 413-420, 1994.

19. Kahn J.O., Gorelick K.J., Gatti G., Arri C.J., Lifson J.D., Gambertoglio J.G., Bostrom A. and Williams R., Safety, activity, and pharmacokinetics of GLQ223 in patients with AIDS and AIDS-related complex. Antimicrob. Agents Chemother. 38: 260-267, 1994. 
20. Cai X., Yao G., Xu G., Yang C., Xu H., Lin Y., Yu J. and Sun B., Identification of the amino acid residues in trichosanthin crucial for IgE response. Biochem. Biophys. Res. Commun. 297: 510-516, 2002.

21. Xiong J.P., Xia Z.X. and Wang Y., Crystal structure of trichosanthin-NADPH complex at 1.7 A resolution reveals active-site architecture. Nat. Struct. Biol. 1: 695-700, 1994.

22. Zhou K., Fu Z., Chen M., Lin Y. and Pan K., Structure of trichosanthin at 1.88 A resolution. Proteins 19: 4-13, 1994.

23. Ho S.N., Hunt H.D., Horton R.M., Pullen J.K. and Pease L.R., Site-directed mutagenesis by overlap extension using the polymerase chain reaction. Gene 77: 51-59, 1989.

24. Pelham H.R. and Jackson R.J., An efficient mRNAdependent translation system from reticulocyte lysates. Eur. J. Biochem. 67: 247-256, 1976.

25. Wang Y.S., Youngster S., Grace M., Bausch J., Bordens R. and Wyss D.F., Structural and biological characterization of pegylated recombinant interferon alpha- $2 b$ and its therapeutic implications. Adv. Drug Deliv. Rev. 54: 547570, 2002.

26. Bailon P., Palleroni A., Schaffer C.A., Spence C.L., Fung W.J., Porter J.E., Ehrlich G.K., Pan W., Xu Z.X., Modi M.W., Farid A., Berthold W. and Graves M., Rational design of a potent, long-lasting form of interferon: a
$40 \mathrm{kDa}$ branched polyethylene glycol-conjugated interferon alpha-2a for the treatment of hepatitis C. Bioconjug. Chem. 12: 195-202, 2001.

27. Ajisaka K. and Iwashita Y., Modification of human hemoglobin with polyethylene glycol: a new candidate for blood substitute. Biochem. Biophys. Res. Commun. 97: 1076-1081, 1980.

28. Tsutsumi Y., Tsunoda S., Kamada H., Kihira T., Kaneda Y., Ohsugi Y. and Mayumi T., PEGylation of interleukin-6 effectively increases its thrombopoietic potency. Thromb. Haemost. 77: 168-173, 1997.

29. Harker L.A., Marzec U.M., Novembre F., Sundell I.B., Waller E.K., Karpatkin S., McClure H.M., Kelly A.B. and Stead R.B., Treatment of thrombocytopenia in chimpanzees infected with human immunodeficiency virus by pegylated recombinant human megakaryocyte growth and development factor. Blood 91: 4427-4433, 1998.

30. Tsunoda S., Ishikawa T., Yamamoto Y., Kamada H., Koizumi K., Matsui J., Tsutsumi Y., Hirano T. and Mayumi T., Enhanced antitumor potency of polyethylene glycolylated tumor necrosis factor-alpha: a novel polymer-conjugation technique with a reversible amino-protective reagent. J. Pharmacol. Exp. Ther. 290: 368-372, 1999. 